them, and that such an extension "cannot therefore have ex. isted." Moreover, the beautiful map of ocean depths with which the volume is illustrated shows a somewhat less depth than 2,000 fathoms on a slightly curved line between the islands, and I believe about the same depth exists between Madagascar and Africa, which have certainly at one time been joined.

There are some other matters touched upon on which I still venture to differ from my reviewer, especially as to the marvellous character of the Easter Island and other remains, and as to the value of the substitution of more for less liberal sectarian teaching in the Sandwich Islands; but on these points I have quoted authorities of considerable weight, and I leave my readers to form their own opinion. As to all matters of fact, I gladly accept correction from one who evidently writes with the advantage of a personal acquaintance with most of the countries referred to in his article.

ALFRED R. WALLACE

\section{Climatal Effects of Eccentricity}

I AM grateful to Dr. Croll for noticing my letter. But I continue to think that if what seems to me to be the fundamental proposition of his theory, and which I quoted at the beginning of my former letter, be correct, and if the manner in which he and his reviewer have applied it be likewise correct, then we ought to find those differences in the air temperatures which my equations indicate. I say air-temperatures, because in Dr. Croll's theory changes of climate are referred to the varying distance of the sun, and climate depends on the temperature of the air.

The heating effect of the sun, other things being equal, has been hitherto assumed to be proportional to the excess of the temperature of the place above the temperature of space. A remarkable result which Pouillet had arrived at, and of which I was not aware when I wrote, shows that this method is incorrect. And I believe that what follows will to some extent afford a reply to the question which I have propounded, and at the same time have a proportionate bearing on Dr. Croll's theory. I quote Pouillet's words from the translation in Taylor's "Scientific Memoirs," vol. iv. p. 83

"The total quantity of heat which space transmits in the course of a year to the earth and to the atmosphere . . . . would be capable of relting upon our globe a stratum of ice of 26 metres thickness. We have seen that the quantity of solar heat is expressed by a stratum of ice of $3 \mathrm{I}$ metres. Thus, together, the earth receives a quantity of beat represented by a stratum of ice of 57 metres; and the heat of space concurs in this for a quantity which is five-sixths of the solar heat. Between the tropics the heat of space is only two-thirds of the solar heat; for the latter is there represented by a stratum of ice of 39 metres."

These surprising results arise from the unequal absorption exercised by the atmosphere upon the heat rays proceeding from the stars and from the earth respectively.

It appears then, that, in applying Dr. Croll's proposition, we ought not to use the value of the temperature of space in forming our proportion, but we ought to use the temperature which the surface of the ground would assume were the sun extinguished. This Pouillet puts at $-89^{\circ}$, or $-128^{\circ} \mathrm{F}$. The substitution of 128 for S., instead of 239 , reduces my calculated difference between the January and July temperatures at the equator to I I F., i.e., by about one-half.

If we make the same correction in the case, the high eccentri. city at aphelion, for which the Quarterly Reviezver has calculated the January temperature of England, and found it $3^{\circ} \mathrm{F}$. (I make it even lower), the new temperature comes out $17^{\circ} \mathrm{F}$., which can hardly be thought low enough to cause any extreme difference from the present climate.

O. FISHER

October 25

THE statement quoted by Mr. Fisher from Dr. Croll (NATURE, vol. $x x, p, 577)$ that "the temperature of a place, other things being equal, is proportional to the heat received from the sun," is based on the assumption of Newton's law of cooling, viz., that the rate of cooling of a body is proportional to the excess of its temperature above that of the surrounding medium. This is approximately true only when the excess is small. When the excess becomes large the rate of cooling augments much more than in proportion. The amount of heat which must be supplied to a body in order to maintain it above the temperature of the surrounding medium is proportional to what would be its rate of cooling. Hence this amount increases as the excess of tempera. ture increases-proportionally while the excess remains small, but much more than proportionally when it becomes large. Conversely, the temperature increases more slowly than the amount of heat supplied, and any variation in the supply will affect the temperature produced in a degree which is less for a large excess than for a small one, and, therefore, less than Newton's rule would give. The excess of the earth's mean temperature above that of space is large, and consequently calculations of changes based on Newton's rule must be in excess of the truth.

The formula obtained by MM. Dulong and Petit (Stewart on "Heat," Art. 235) from the rate of cooling of a thermometerbulb in vacuo makes the necessary supply of heat proportional to $\left(\mathrm{I} \cdot 0077^{t}-\mathrm{I}\right)$, where $t$ is the excess of temperature in Centigrade degrees. If we apply this to the case lof the earth, and take $80^{\circ} \mathrm{F}$. as temperature at the equator when the earth is at its mean distance from the sun, then the resulting temperatures at its greatest and least distances with our present eccentricity, are given as about $74^{\circ}$ and $85^{\circ}$ respectively. The fluctuation, which Mr. Fisher makes $2 I^{\circ}$, is reduced to about $1 I^{\circ}$. The fall in temperature which would follow a stoppage of the Gulf Stream is made by Newton's rule $59^{\circ}$ ("Climate and Time," p. 36): the more accurate formula reduces this to about $37^{\circ}$. Dr. Croll suggests that the temperature of space mcy be lower than is usually assumed (p. 37). If it be taken as absolute zero $\left(-459^{\circ}\right.$ F.) the fall would not even then come out much greater than $45^{\circ} \mathrm{F}$.

Several of Dr. Croll's tables shonld be similarly modified; at the same time it would be scarcely correct to say that these changes "touch Dr. Croll's theory somewhat closely." They do not invalidate the general contention, that a diminution of the Gulf Stream must diminish the mean temperature of northern regions to a very serious degree.

St. John's College, Cambridge, October 25

The Weather and the Sun

Prof. Piazzr Smyth in his communication to Nature, vol. $\mathrm{xx} . \mathrm{p} .43 \mathrm{I}$, evidently infers that changes in the condition of the sun must needs affect every part of the earth in the same way, whereas we have many meteorological analogies, which favour the notion that totally opposite effects may arise in different parts of the earth from the action of the same primary causes. For example, it is generally assumed that the same tropical heat which gives the primary impulse to the desiccating north-east trade wind of sub-tropical latitudes, furnishes the energy which exlibits itself in the almost constant precipitation under the equator. Any variation in the degree of this heat, should consequently affect localities situated in the region of the trades, and the equatorial calm-belt, in a diametrically opposite manner: Moreover, the notion that the British and Indian rain falls vary together now is altogether inconsistent with the well-known want of similarity between them, both as regards seasonal distribution and annual quantity in the past. It is also remarkable that while the present deluge both here and in India is traced to the sun's "recovering his forces and beginning already to shine after his recent languid spotless years with increased radiation on the great oceans of the south," the rainfall of England between latitudes $50^{\circ}$ and $55^{\circ} \mathrm{N}$. reached a decided maximum in 1877 , the year when the sun was, to adopt the favourite metaphor, affected with the most extreme languor, and has been very high all through the period of unusually marked spot minimum, from which we are but just emerging.

The following figures from Mr. Glaisher's reports will illustrate what I have just said.

\begin{tabular}{llllll} 
Great Britain, Lat. $50^{\circ}-55^{\circ} \mathrm{N}$. \\
Years. & & & \multicolumn{3}{c}{ Rainfall in inches. } \\
1875 & $\ldots$ & $\ldots$ & $\ldots$ & $\ldots$ & $34^{\circ} 04$ \\
1876 & $\ldots$ & $\ldots$ & $\ldots$ & $\ldots$ & $34^{\circ} 60$ \\
1877 & $\ldots$ & $\ldots$ & $\ldots$ & $\ldots$ & $3^{8} \cdot 55$ \\
1878 & $\ldots$ & $\ldots$ & $\ldots$ & $\ldots$ & $3^{2} \cdot 6 \mathrm{r}$
\end{tabular}

More valuable results will generally accrue to science if, instead of founding vague hypotheses on a fancied likeness between isolated weather conditions, at places where the prime meteorological factors act in a totally dissimilar manner; induction is made from results which are derived from trustworthy data, and anticipated by a knowledge of admitted physical principles. As an example of this latter kind, allow me to conclude this letter by exhibiting 